Mal J Nutr 26(1): 085-092, 2020

\title{
Identification of dietary diversity associated with stunting in Indonesia
}

\author{
Laksmi Trisasmita*, Trini Sudiarti, Ratu Ayu Dewi Sartika \& Asih Setiarini \\ Department of Nutrition, Faculty of Public Health, Universitas Indonesia
}

\begin{abstract}
Introduction: Stunting has become one of the world's most discussed health topics. Dietary diversity takes on an important role in increasing the nutrition fulfilment of young children aged 6-59 months for their optimal growth. This study aims to understand the association between dietary diversity and stunting in children aged 6-59 months old in Babakan Madang subdistrict, Bogor district of West Java, Indonesia. Methods: This study used a cross-sectional design and was conducted in May 2019 in Babakan Madang subdistrict. The subjects chosen for this study were 200 children aged 6-59 months, and they were selected using the probabilityproportional-to-size sampling technique. Individual dietary diversity was assessed by minimum dietary diversity with the consumption of four or more food groups out of the total seven groups. Data were analysed using descriptive statistics and chi-square test. Results: Poor dietary diversity was significantly related with stunting ( $p=0.023 ; O R=2.182 ; 95 \%$ CI: $1.152-4.134$ ). In addition, age $<2$ years was a significant protective factor against stunting $(p=0.011 ; O R=0.445 ; 95 \%$ CI: $0.246-$ 0.806). Conclusion: The risk of stunting in children can be reduced by providing a variety of foods in their diets, which includes at least four food groups a day. There is a need to increase awareness among the population about appropriate nutrition through dietary education.
\end{abstract}

Keywords: Stunting, dietary diversity, child nutrition

\section{INTRODUCTION}

Lost generation is a threat due to the increased incidence of stunting caused by suboptimal growth in children. Moreover, stunting is also linked with the risk of higher morbidity and mortality, as well as lower human development and productivity later in life (Prendergast \& Humphrey, 2014). The Global Nutrition Report says that the world cannot afford not to act on nutrition: it is a critical linchpin for the global effort to end poverty and achieve sustainable development (Fanzo et al.,
2018). As a result, "stunting" has caught the attention of international nutrition and child health research, programmes, and policy circles (Perumal, Bassani \& Roth, 2018).

In 2018, the worldwide statistics showed that just under one in four children $(21.9 \%)$ aged $<5$ years has stunted growth (IFPRI, 2016). That said, overall trends are positive. The prevalence of stunting in young children in Indonesia was $30.8 \%$ in 2018. This prevalence is still much higher than the predetermined target

\footnotetext{
*Corresponding author: Laksmi Trisasmita Department of Nutrition, Universitas Indonesia, Depok, Indonesia Tel: +6285340509757; E-mail: laksmi.sasmita@gmail.com doi: https://doi.org/10.31246/mjn-2019-0128
} 
of $28 \%$ envisaged in the Indonesia medium-term development plan 2019 (Kemenkes RI, 2018a). Meanwhile, the World Health Organization (WHO) targets a $40 \%$ reduction in the number of children under 5 who are stunted by 2025 (WHO/Antonio, 2014). Indonesia needs to make a serious effort to reduce its stunting problem in the country in order to circumvent the degraded quality of human capital that results from stunting (Paramashanti, Paratmanitya \& Marsiswati, 2017).

Stunting is caused by two main causes - direct and indirect causes. The direct causes and aetiology of stunting include chronic inadequate diet (energy, macronutrients, and micronutrients) and infections (Frongillo, 1999). Quantity and quality of diet can be predicted by the diversity of foods consumed at the individual or household level to assess for nutrient adequacy (Krasevec, Kumapley \& Frongillo, 2017). Toddlers should be given a variety of foods to support motor development and avoid mental disorders (Saaka, Osman \& Hoeschle-Zeledon, 2017). Indirect causes such as age group, mother's parity, time of complementary feeding, age during pregnancy, and exclusive breastfeeding are also associated with stunting. The age group of $<2$ years is often considered to be associated with stunting. Mother's parity and age are also strongly associated with stunting in a child's first 5 years of life, particularly in post-stunting linear growth (Faye, Fonn \& Levin, 2019). Furthermore, exclusive breastfeeding and complementary food should also be considered (Zhou et al., 2012).

Although children $<5$ years should be introduced to dietary diversity (Rah et al., 2010), in developing countries, including Indonesia, food intake is still primarily dominated by calorie-source foods and deficient in animal food sources, fruits and vegetables (Masibo
\& Ochola, 2014). Food diversity in children, measured by individual dietary diversity score (IDDS), can be used as a predictor of stunting (Saaka et al., 2017). According to previous studies, dietary diversity is related to the incidence of stunting, but other studies did not find the same results. Therefore, this study aims to address the association between dietary diversity and stunting in children aged 6-59 months.

\section{MATERIALS AND METHODS}

This study used a cross-sectional design. It was conducted in May 2019 in Babakan Madang subdistrict, Bogor district, West Java, Indonesia. The sample was 200 young children aged 6-59 months who were residents of Babakan Madang subdistrict. They were selected using the probability-proportional-to-size sampling technique where the Posyandu or Integrated Healthcare Center was used as cluster. The selected subjects were those who have signed an informed consent before data were collected.

Stunting was defined as an anthropometric status of length-for-age $z$-score of <-2 SD in children (Kemenkes RI, 2018b). Variables such as mother's parity, age group, time of complementary feeding, exclusive breastfeeding, mother's age during pregnancy, and child's history of infections were collected through interviews using a structured questionnaire. The questionnaire was tested beforehand for its validity and reliability. This study was approved by the Ethical Committee Faculty of Public Health, Universitas Indonesia, under the approval No. 257/UN2.F10/ PPM/00.02/2019.

Information on dietary diversity was obtained from mothers using a 24hour food recall, which was collected by using an adapted food groups check list based on foods consumed as usual diet on the previous 24 hours. Then, 
using the individual dietary diversity questionnaire, foods were classified into seven groups based on the WHO indicators, namely: 1. Grains, roots and tubers, 2. Legumes and nuts, 3. Dairy products, 4. Meat, fish, poultry, and liver/organ meats, 5. Eggs, 6. Vitamin A-rich fruits and vegetables, 7. Other fruits and vegetables. Besides using data from 24-hour food recalls, dietary diversity was also assessed by asking the mothers on whether their child had received foods from the standard seven groups in the preceding day, without setting any minimum intake restrictions. Dietary diversity was calculated as the sum of food groups in the diet, which was considered "good" when subjects consumed four or more food groups, and "poor" when they consumed less than four food groups (FAO, 2011). Univariate analysis was conducted using descriptive statistics and the associations between variables were analyzed using chisquare test.

Table 1. Demographic and socio-behavioral characteristic of maternal and children

\begin{tabular}{|c|c|c|}
\hline Variable & $n$ & $\%$ \\
\hline \multicolumn{3}{|l|}{ Nutritional status } \\
\hline Stunting & 69 & 34.5 \\
\hline Normal & 131 & 65.5 \\
\hline \multicolumn{3}{|l|}{ Individual dietary diversity } \\
\hline Poor & 125 & 62.5 \\
\hline Good & 75 & 37.5 \\
\hline \multicolumn{3}{|l|}{ Age group } \\
\hline$<2$ years & 113 & 56.5 \\
\hline$\geq 2$ years & 87 & 43.5 \\
\hline \multicolumn{3}{|l|}{ Complementary feeding time } \\
\hline Not appropriate $(<6$ or $>6$ mos.) & 124 & 62.0 \\
\hline Appropriate (6 mos.) & 76 & 38.0 \\
\hline \multicolumn{3}{|l|}{ Exclusive breastfeeding } \\
\hline Yes & 77 & 38.5 \\
\hline No & 123 & 61.5 \\
\hline \multicolumn{3}{|l|}{ Mother's parity } \\
\hline Less & 62 & 31.0 \\
\hline More & 138 & 69.0 \\
\hline \multicolumn{3}{|l|}{ Mother's age during pregnancy } \\
\hline Risky & 66 & 33.0 \\
\hline Not risky & 134 & 67.0 \\
\hline \multicolumn{3}{|l|}{ Child's history of infections } \\
\hline Yes & 72 & 36.0 \\
\hline No & 128 & 64.0 \\
\hline
\end{tabular}




\section{RESULTS}

The number of subjects in this study was 200 children aged 6-59 months, who were domiciled in the Babakan Madang subdistrict, Bogor district, West Java, Indonesia. The subjects were mostly aged $<2$ years $(56.5 \%)$ and dominated by boys $(53.5 \%)$. Most mothers of the subjects did not have any jobs or were housewives $(93.0 \%)$ and had completed a minimum of elementary school education (84.0\%).
The subjects' fathers mostly worked as labourers or were in service $(82.2 \%)$ and had completed a minimum of senior high school education (35.0\%) (Table 1).

The prevalence of stunting in this study was $34.5 \%$, and $62.5 \%$ of the children had poor dietary diversity. Responses to the questionnaire showed that only about $38.5 \%$ of the mothers in the study practised exclusive breastfeeding, and this was similar to the

Table 2. Dietary diversity and other factors associated with stunting ( $n=200)$

\begin{tabular}{|c|c|c|c|c|c|c|c|}
\hline \multirow{3}{*}{ Variable } & \multicolumn{4}{|c|}{ Stunting } & \multirow{3}{*}{ OR } & \multirow{3}{*}{ p-value } & \multirow{3}{*}{$95 \% C I$} \\
\hline & \multicolumn{2}{|c|}{ Yes } & \multicolumn{2}{|c|}{ No } & & & \\
\hline & $n$ & $\%$ & $n$ & $\%$ & & & \\
\hline \multicolumn{8}{|l|}{ Individual dietary diversity } \\
\hline Poor & 51 & 40.8 & 74 & 59.2 & 2.182 & $0.023^{*}$ & $1.152-4.134$ \\
\hline Good & 18 & 24.0 & 57 & 76.0 & & & \\
\hline \multicolumn{8}{|l|}{ Age group } \\
\hline$<2$ years & 30 & 26.5 & 83 & 73.5 & 0.445 & $0.011^{*}$ & $0.246-0.806$ \\
\hline$\geq 2$ years & 39 & 44.8 & 48 & 55.2 & & & \\
\hline \multicolumn{8}{|l|}{ Complementary feeding time } \\
\hline $\begin{array}{l}\text { Not appropriate }(<6 \text { or }>6 \\
\text { mos.) }\end{array}$ & 46 & 37.1 & 78 & 62.9 & 1.359 & 0.405 & $0.738-2.501$ \\
\hline Appropriate (6 mos.) & 23 & 30.3 & 53 & 69.7 & & & \\
\hline \multicolumn{8}{|l|}{ Exclusive breastfeeding } \\
\hline No & 48 & 39.0 & 75 & 61.0 & 1.707 & 0.086 & $0.919-3.168$ \\
\hline Yes & 21 & 27.3 & 56 & 72.7 & & & \\
\hline \multicolumn{8}{|l|}{ Mother's parity } \\
\hline Less & 24 & 38.7 & 38 & 61.3 & 1.305 & 0.497 & $0.700-2.433$ \\
\hline More & 45 & 32.6 & 93 & 67.4 & & & \\
\hline \multicolumn{8}{|l|}{$\begin{array}{l}\text { Mother's age during } \\
\text { pregnancy }\end{array}$} \\
\hline Risky & 22 & 33.3 & 44 & 66.7 & 0.926 & 0.932 & $0.497-1.725$ \\
\hline Not risky & 47 & 35.1 & 87 & 64.9 & & & \\
\hline \multicolumn{8}{|l|}{ Child's history of infections } \\
\hline Yes & 27 & 37.5 & 45 & 62.5 & 0.814 & 0.607 & $0.445-1.488$ \\
\hline No & 42 & 32.8 & 86 & 67.2 & & & \\
\hline
\end{tabular}

Note: $p$-value is the significance of chi-squared test; OR is odds ratio; $\mathrm{CI}$ is confidence interval ${ }^{*} p<0.05$ 
appropriate complementary feeding time of 6 months (38.0\%). Nonetheless, more than half of the children did not have a history of having infectious diseases (64.0\%). Most mothers of the subjects had a history of previous childbirth, i.e. high parity (69.9\%), and their age during pregnancy was classified as non-risky (67.0\%) (Table 2).

Bivariate analysis showed that there were two variables that had significant associations with stunting: poor individual dietary diversity $(p=0.023$; $O R=2.182 ; 95 \% \mathrm{CI}: 1.152-4.134)$ and age group $<2$ years $(p=0.011 ; O R=0.445$; 95\% CI: 0.246-0.806). The results also showed that age group $<2$ years had a significant association with poor dietary diversity $\quad(p=0.002 ; \quad O R=2.474 ; \quad 95 \%$ CI: 1.367-4.447). In comparison, time of complementary feeding, exclusive breastfeeding, mother's parity, mother's age during pregnancy, and child's history of infections were not associated with stunting.

\section{DISCUSSION}

Globally, linear growth deficit in children is a nutritional problem. Results in this study indicated that the percentage of children aged 6-59 months who were stunted was $34.5 \%$. Moreover, the 2017 Nutritional Status Assessment in West Java showed that $29.6 \%$ of the children were stunted, an increase of $2.1 \%$ from the previous year (Kemenkes RI, 2017). According to WHO, a region is classified as having a severe problem if the prevalence of stunting is around $30 \%-39 \%$, and a serious problem if the prevalence of stunting is $>40 \%$ (WHO, 2010). Stunting can have a very bad impact on children's growth, especially related to their cognitive, motor, and emotional functions, as well as their future potential (Walker et al., 2007).

Stunting can be caused by several factors, one of which is food intake. Based on the results of this study, it was seen that children who consumed $<4$

Table 3. Dietary diversity and other factors associated with stunting $(n=200)$

\begin{tabular}{|c|c|c|c|c|c|c|c|}
\hline \multirow{3}{*}{ Variable } & \multicolumn{4}{|c|}{ Dietary Diversity } & \multirow{3}{*}{$O R$} & \multirow{3}{*}{ p-value } & \multirow{3}{*}{$95 \% C I$} \\
\hline & \multicolumn{2}{|c|}{ Poor } & \multicolumn{2}{|c|}{ Good } & & & \\
\hline & $n$ & $\%$ & $n$ & $\%$ & & & \\
\hline \multicolumn{8}{|l|}{ Age group } \\
\hline$<2$ years & 81 & 71.7 & 32 & 28.3 & 2.474 & $0.002 *$ & $1.367-4.447$ \\
\hline$\geq 2$ years & 44 & 50.6 & 43 & 49.4 & & & \\
\hline \multicolumn{8}{|l|}{ Complementary feeding time } \\
\hline $\begin{array}{l}\text { Not appropriate }(<6 \text { or }>6 \\
\text { mos.) }\end{array}$ & 83 & 66.9 & 41 & 33.1 & 1.639 & 0.098 & $0.911-2.947$ \\
\hline Appropriate (6 mos.) & 42 & 55.3 & 34 & 44.7 & & & \\
\hline \multicolumn{8}{|l|}{ Exclusive breastfeeding } \\
\hline No & 67 & 54.5 & 56 & 45.5 & 1.845 & 0.082 & $1.194-2.852$ \\
\hline Yes & 58 & 75.3 & 19 & 27.4 & & & \\
\hline \multicolumn{8}{|l|}{ Child's history of infections } \\
\hline Yes & 80 & 62.5 & 48 & 37.5 & 1.000 & 1.000 & $0.551-1.816$ \\
\hline No & 45 & 62.8 & 27 & 37.5 & & & \\
\hline
\end{tabular}


groups of foods had a 2.18 times higher risk of becoming stunted compared to children who consumed $>4$ groups of foods. This result is in agreement with a previous study conducted in Namibia $(\mathrm{OR}=1.095 ; 95 \% \mathrm{CI}: 1.021-1.174)$, and is reinforced by the results of a study in Sedayu Yogyakarta $(O R=12.11 ; 95 \%$ CI: 5.83-25.10) (Paramashanti et al., 2017). The higher the score of diversity in food consumption, the more diverse the types of foods consumed by children. Thus, the variety of foods consumed will tend to meet the adequacy of nutrients that can affect the nutritional status of children (Habte \& Krawinkel, 2016).

Dietary diversity in children must cover at least four of the seven food groups, which must consist of staple foods, side dishes, vegetables and fruits (Wantina, Rahayu \& Yuliana, 2017). In addition, the variety in foods should also be introduced early in children under $<5$ years old because every food group contains essential nutrients that can complete their nutritional needs (Rah et al., 2010). In this study, children mostly consumed $<4$ food groups per day $(62.5 \%)$. There were even cases where the mothers gave their children only three food groups in a day, including breast milk. In fact, sometimes children were given the same type of food consecutively for several days. The majority of the children $(87.0 \%)$ consumed grains, such as rice and bread, while consumption of eggs, legumes and animal source foods were low. Animal source foods like meat, milk and eggs have a variety of micronutrients including vitamin $\mathrm{A}$, vitamin B-12, riboflavin, calcium, iron and zinc that are difficult to obtain in adequate quantities from plant source foods alone (Khamis et al., 2019).

Several previous studies showed results that were different from those obtained in this study, such as studies conducted in Bangladesh and Cambodia. Both of these showed an association between dietary diversity and stunting, but the power of association was quite weak (Darapheak et al., 2013; Rah et al., 2010). These differences could have been caused by differences in the instruments used. In these studies, household dietary diversity score (HDDS) was used, which does not have specific and relevant targets in any population group; whereas this study used the individual dietary diversity score (IDDS), which targets children more specifically because of the importance given to micronutrient adequacy for growth and development (Mark \& Agnes, 2008). IDDS was used as a measure of nutritional quality for every subject to reflect nutrient adequacy.

Our analyses showed that children $<2$ years of age were significantly protected from being stunted than children aged $\geq 2$ years. However, this does not prove that they will be free from stunting. The difficulty in clearly detecting the occurrence of stunting in children aged $<2$ years is one of the main factors that causes a greater risk of stunting in children aged $\geq 2$ years. The suboptimal growth related to increased age might be derived from the challenges associated with the feeding transition from breastfeeding to complementary feeding (Titaley et al., 2019). On the other hand, we found that children aged $<2$ years had a significantly increased likelihood of having poor dietary diversity than those aged $\geq 2$ years. Previous studies have found that younger children were significantly associated with inadequate dietary diversity; and it can been related to the delay in the initiation of complementary feeding in the form of solid, semi-solid or soft foods (Custodio et al., 2019). This makes stunting possible in children aged $<2$ years.

Children with stunting at $<2$ years were reported to experience worse psychological functions (more anxious and depressed) in adolescence than children who were not stunted at $<2$ 
years of age (Darapheak et al., 2013). In addition, it has been reported that such stunting can also cause hyperactive behaviours and increase the levels of opposition or aggression in children (Walker et al., 2007).

The growth process in children aged $\geq 2$ years tend to be slower, thus the chance for catch-up growth would be lower than children aged $<2$ years (Darapheak et al., 2013). Age $>2$ years is the time when children grow rapidly in their cognitive and motor developments. Therefore, peak physical condition, which can only be attained through appropriate nutrition, is needed to support these developments (Darapheak et al., 2013; Zottarelli, Sunil \& Rajaram, 2007). Increasing age must be accompanied by an increasing diversity of foods consumed (FAO, 2011). So, children at this age also need more attention than children $<2$ years in terms of food intake because of their needs for higher energy and more varied foods for nutrient fulfilment.

\section{CONCLUSION}

The results of this study showed that there was a strong association between dietary diversity and stunting in children aged 6-59 months in Babakan Madang subdistrict of Indonesia. Individual dietary diversity score can be used as an indicator of dietary quality. Children who did not eat a variety of foods and thus had poor food intake bore 2.18 times higher risk of being stunted compared with children who had good food intakes. Finally, dietary education would be the most effective strategy to deliver messages about child feeding practices, especially on dietary diversity.

\section{Acknowledgement}

The first author is grateful to Bambang Wispriyono as a lecturer of Universitas Indonesia for helpful consultations throughout the process of planning, writing, and finishing this paper.

\section{Authors' contributions}

LT, conducted the study, data analysis and interpretation, prepared the draft of the manuscript, assisted in drafting of the manuscript, reviewed the manuscript; TS, led the data collection, conceptualised and design the study, reviewed the manuscript; RADS, led the data collection, advised on the data analysis and interpretation and reviewed the manuscript; AS, advised on the data analysis and interpretation and reviewed the manuscript.

\section{Conflict of interest}

The authors declare that there were no conflicts of interest in this study.

\section{References}

Custodio E, Herrador Z, Nkunzimana T, WęziakBiałowolska D, Perez-Hoyos A \& Kayitakire F (2019). Children's dietary diversity and related factors in Rwanda and Burundi: A multilevel analysis using 2010 Demographic and Health Surveys. PLOS ONE 14(10):1-17. https://doi. org/10.1371/journal.pone.0223237

Darapheak C, Takano T, Kizuki M, Nakamur K \& Seino K (2013). Consumption of animal source foods and dietary diversity reduce stunting in children in Cambodia. Int Arch Med 6(1):1. https:/ / doi.org/ 10.1186/1755-7682-6-29

Fanzo J, Hawkes C, Udomkesmalee E, Afshin A, Allemandi L \& Assery O (2018). Global Nutrition Report. In Global Nutrition Report (Issue June). https://doi.org/http://dx.doi. org/ 10.2499/9780896295643

FAO (2011). Guidelines for measuring household and individual dietary diversity. Food and Agriculture Organization, European Union.

Faye CM, Fonn S \& Levin J (2019). Factors associated with recovery from stunting among under-five children in two Nairobi informal settlements. PLoS ONE 14(4):1-17. https://doi. org/10.1371/journal.pone.0215488

Frongillo EA (1999). Symposium: causes and etiology of stunting. Introduction. $J$ Nutr 129(2S Suppl):529S-530S

Habte TY \& Krawinkel M (2016). Dietary diversity score: a measure of nutritional adequacy or an indicator of healthy diet? $J$ Nutr Health Sci 3(3):15-17. https://doi.org/10.15744/23939060.3.303

IFPRI (2016). Global Nutrition Report 2016: From Promise to Impact: Ending Malnutrition by 2030. International Food Policy Research Institute. Washington, DC. 
Kemenkes RI (2017). Hasil Pemantauan Status Gizi (PSG) Tahun 2016. Kementerian Kesehatan Republik Indonesia, Jakarta.

Kemenkes RI (2018a). Hasil Utama Riset Kesehatan Dasar 2018. Kementrian Kesehatan Republik Indonesia, Jakarta.

Kemenkes RI (2018b). Situasi Balita Pendek (Stuntin) di Indonesia. Kementerian Kesehatan Republik Indonesia, Jakarta.

Khamis A G, Mwanri AW, Ntwenya JE \& Kreppel K (2019). The influence of dietary diversity on the nutritional status of children between 6 and 23 months of age in Tanzania. BMC Pediatrics 19(1):1-9. https://doi.org/10.1186/s12887019-1897-5

Krasevec J, Kumapley R \& Frongillo EA (2017). Diet quality and risk of stunting among infants and young children in low- and middle- income countries. Matern Child Nutr 13:1-11. https:// doi.org/10.1111/mcn. 12430

Mark S \& Agnes D (2008). Fact sheets on food and nutrition security indicators/measures: dietary diversity (DD). United Nations System Standing Committee on Nutrition, Task Force on Assessment, Monitoring and Evaluation.

Masibo PK \& Ochola S (2014). Dietary intake of schoolchildren and adolescents in developing countries. Annals of Nutrition \& Metabolism 64:499-505. https://doi. org/10.1159/000365125

Paramashanti BA, Paratmanitya Y \& Marsiswati M (2017). Individual dietary diversity is strongly associated with stunting in infants and young children. Jurnal Gizi Klinik Indonesia 14(1): 19. https://doi.org/ 10.22146/ijcn.15989

Perumal N, Bassani DG \& Roth DE (2018). Use and misuse of stunting as a measure of child health. Journal of Nutrition 148(3):311-315. https://doi.org/10.1093/jn/nxx064

Prendergast AJ \& Humphrey JH (2014). The stunting syndrome in developing countries. Paediatrics and International Child Health 34(4):250-265. https://doi.org/10.1179/2046 905514Y.0000000158
Rah JH, Akhter N, Semba RD, de Pee S, Bloem MW, Campbell AA, Sun K, Badham J \& Kraemer K (2010). Low dietary diversity is a predictor of child stunting in rural Bangladesh. Eur J Clin Nutr 64(12):1393-1398. https: / / doi. org/10.1038/ejcn.2010.171

Saaka M, Osman SM \& Hoeschle-Zeledon I (2017). Relationship between agricultural biodiversity and dietary diversity of children aged 6-36 months in rural areas of northern Ghana. Food and Nutrition Research 61. https://doi.org/10. 1080/16546628.2017.1391668

Titaley CR, Ariawan I, Hapsari D, Muasyaroh A \& Dibley MJ (2019). Determinants of the stunting of children under two years old in Indonesia: a multilevel analysis of the 2013 Indonesia basic health survey. Nutrients 11(5):1106. https:// doi.org/10.3390/nu11051106

Walker SP, Chang SM, Powell CA, Simonoff E \& Grantham-Mcgregor SM (2007). Early childhood stunting is associated with poor psychological functioning in late adolescence and effects are reduced by psychosocial stimulation. J Nutr 137(11):2464-2469.

Wantina M, Rahayu LS \& Yuliana I (2017). Keragaman konsumsi pangan sebagai faktor risiko stunting pada balita usia 6-24 bulan. Journal UHAMKA 2(2):89-96.

WHO (2010). Nutrition Landscape Information System (NLIS) country profile indicators: interpretation guide. World Health Organization, Geneva.

WHO/Antonio SW (2014). WHA Global Nutrition Targets 2025: Stunting Policy Brief. World Health Organization.

Zhou $\mathrm{H}$, Wang XL, Ye F, Zeng XL \& Wang Y (2012). Relationship between child feeding practices and malnutrition in 7 remote and poor counties, P R China. Asia Pac J Clin Nutr 21(2):234-240.

Zottarelli LK, Sunil TS \& Rajaram S (2007). Influence of parental and socioeconomic factors on stunting in children under 5 years in Egypt. East Mediterr Health J 13(6):1330-1342. 